CLINICAL STUDY

\title{
Routine screening for Cushing's syndrome is not required in patients presenting with hirsutism
}

\author{
$\mathrm{Z} \mathrm{Karaca}^{1}$, B Acmaz ${ }^{1}$, G Acmaz $^{3}$, F Tanriverdi ${ }^{1}$, K Unluhizarci ${ }^{1}$, S Aribas ${ }^{1}$, Y Sahin $^{2}$ and F Kelestimur ${ }^{1}$ \\ Departments of ${ }^{1}$ Endocrinology and ${ }^{2}$ Obstetrics and Gynecology, Erciyes University Medical School, 38039 Kayseri, Turkey and ${ }^{3}$ Department of Obstetrics \\ and Gynecology, Kayseri Training and Research Hospital, Kayseri, Turkey \\ (Correspondence should be addressed to F Kelestimur; Email: fktimur@erciyes.edu.tr)
}

\begin{abstract}
Context: Prevalence of Cushing's syndrome (CS) in patients presenting with hirsutism is not well known.

Objective: Screening of CS in patients with hirsutism.

Setting: Referral hospital.

Patients and other participants: This study was carried out on 105 patients who were admitted to the Endocrinology Department with the complaint of hirsutism.

Intervention: All the patients were evaluated with low-dose dexamethasone suppression test (LDDST) for CS.

Main outcome measure: Response to LDDST in patients presenting with hirsutism.

Results: All the patients had suppressed cortisol levels following low-dose dexamethasone administration excluding CS. The etiology of hirsutism was polycystic ovary syndrome in $79 \%$, idiopathic hirsutism in 13\%, idiopathic hyperandrogenemia in $6 \%$, and nonclassical congenital hyperplasia in $2 \%$ of the patients.

Conclusion: Routine screening for CS in patients with a referral diagnosis of hirsutism is not required. For the time being, diagnostic tests for CS in hirsute patients should be limited to patients who have accompanying clinical stigmata of hypercortisolism.
\end{abstract}

European Journal of Endocrinology 168 379-384

\section{Introduction}

Hirsutism is the presence of excessive terminal hair in androgen-sensitive skin areas of women. Functional causes such as polycystic ovary syndrome (PCOS), idiopathic hirsutism (IH), and idiopathic hyperandrogenemia (IHA) account for most hirsutism cases. Nonclassical congenital adrenal hyperplasia (NCAH), hyperprolactinemia, androgen-secreting tumors, acromegaly, and Cushing's syndrome (CS) are other rare causes of hirsutism $(1,2)$.

The diagnosis of CS is noteworthy as it leads to significant morbidities and increased mortality. Hypercortisolemia-associated morbidities, particularly increased cardiovascular risk, may persist in a substantial number of CS patients despite normalization of hypercortisolemia $(3,4)$. Increased mortality and morbidities like hypertension, hyperglycemia, increased fat mass, hypercoagulability, decreased bone mineral density and quality, psychopathologies, and cognitive impairment significantly improve after successful treatment of CS, but even after long-term remission, these morbidities and mortality may not be completely reversible (5). Therefore, early diagnosis and treatment is important before the presentation of overt cardiovascular, metabolic, and psychiatric disorders.

CS has previously been screened in different diseases such as diabetes mellitus, obesity, and hypertension with variable outcomes $(6,7,8,9,10)$. Most of the patients diagnosed as CS in these studies were subclinical cases that would be missed unless they were tested.

It is essential to rule out other causes of hirsutism such as CS for the diagnosis of functional causes of hirsutism $(11,12)$. The exclusion of CS is usually based on clinical findings. Although clinical findings may be helpful in the diagnosis of CS in patients with hirsutism, the frequency of CS in patients presenting with hirsutism, who lack physical stigmata suggestive of hypercortisolism, is not well known.

In this study, we primarily aimed to screen CS in patients admitting with the complaint of hirsutism for the first time. 


\section{Materials and methods}

\section{Subjects}

One hundred and five women, who were admitted to the Endocrinology Clinic with hirsutism and accepted to participate in the study, were consecutively enrolled in the study between February 2011 and June 2012. Exclusion criteria were i) being treated for hirsutism in the last 6 months and ii) having any diseases or using any medications that would affect the hypothalamopituitary-adrenal axis.

Patients were evaluated by a detailed medical history, including the onset and characteristics of hirsutism, presence of symptoms regarding etiology, menstrual cycle, and fertility. Hirsutism was assessed with modified Ferriman-Gallwey score (FGS) (13). A score $\geq 8$ was accepted as hirsutism.

\section{Materials and protocols}

All patients were evaluated in follicular phase of their menstrual cycle. If the patient had oligomenorrhea or amenorrhea, evaluation was carried out during withdrawal bleeding induced by medroxyprogesterone acetate. Serum samples for measurement of LH, FSH, estradiol $\left(\mathrm{E}_{2}\right)$, prolactin (PRL), total testosterone, sex hormone binding globulin (SHBG), DHEAS, androstenedione, 17-hydroxyprogesterone (17-OHP), 11-deoxycortisol (11-S), cortisol, free thyroxine $\left(\mathrm{fT}_{4}\right)$ and TSH, and IGF1 levels were obtained in the morning after an overnight fast at baseline.

The ACTH stimulation test was performed in patients by administration of a single i.v. bolus of $250 \mu \mathrm{g}$ synthetic ACTH (Synacthen $0.25 \mathrm{mg} / \mathrm{ml}$; Novartis Healthcare) at $0800 \mathrm{~h}$. Venous blood was drawn through an indwelling catheter at 0,30 , and $60 \mathrm{~min}$ after ACTH administration for the determination of 17-OHP and 11-S. On the luteal phase of the cycle (menstrual days 22-24), progesterone was measured.

The diagnosis of PCOS was made according to ESHRE/ASRM (Rotterdam) criteria (14). Women with cycle lengths of $>35$ days were classified as oligomenorrheic. The ultrasound (USG) diagnosis of polycystic ovaries was made by the presence of ten or more cysts $2-10 \mathrm{~mm}$ in diameter arranged around a dense stroma or scattered throughout an increased amount of stroma (15). Ovarian USG was performed by the same investigator (Y S). IH was diagnosed in patients with hirsutism if they had normal ovulatory functions, normal ovarian morphology on USG, and normal androgen levels. Patients with elevated serum androgen levels in the presence of normal ovulatory functions and normal ovarian morphology were included in IHA group. All the patients with IH or IHA have been shown to be ovulatory by the measurement of day 22-24 serum progesterone level ( $>8 \mathrm{nmol} / \mathrm{l})$. Hyperandrogenemia was defined as increased serum testosterone, androstenedione, and/or DHEAS levels. An ACTHstimulated 17-OHP concentration $>30 \mathrm{nmol} / \mathrm{l}$ $(10 \mathrm{ng} / \mathrm{ml})$ was considered as the criterion for $\mathrm{NCAH}$ due to 21-hydroxylase deficiency $(16,17,18)$. The diagnosis of 11- $\beta$ hydroxylase deficiency was made if the adrenal 11-S response to ACTH stimulation exceeded threefold the 95th percentile of controls (16). The 95th percentile for the 11-S response measured in our healthy subjects was defined as $36.6 \mathrm{nmol} / \mathrm{l}$ $(12.2 \mathrm{ng} / \mathrm{ml})$ previously (19). Patients filling the biochemical criteria of $\mathrm{NCAH}$ were tested for the presence of genetic mutation.

CS was excluded by low-dose dexamethasone suppression test (LDDST). Forty-eight-hour dexamethasone $(2 \mathrm{mg} /$ day) suppression test was used and a cortisol value of $\leq 1.8 \mu \mathrm{g} / \mathrm{dl}$ was considered as normal. Androgen-producing tumors were diagnosed/excluded by the history of rapid-onset hirsutism, highly elevated testosterone and DHEAS levels, and the radiological investigation of the adrenal glands and the ovaries.

\section{Assays}

Testosterone (DIAsource ImmunoAssays, Louvain-laNeuve, Belgium), DHEAS (Immunotech, Marseille, France), androstenedione (DSL-3800, Diagnostic System Laboratories, Inc., Texas, U Costa Mesa, CA, USA), 17-OHP (DSL-3SA, TX, USA), 11-S (DIAsource ImmunoAssays), and cortisol (DSL-2100, TX, USA) were measured by RIA method. Serum SHBG and IGF1 levels were measured by IRMA (SHBG: Zentech, Angleur, Belgium, and non-extraction IGF1 DSL2800, TX, USA). FSH, LH, progesterone, and $\mathrm{E}_{2}$ (ACS:180, Bayer) were measured with a chemiluminescence enzyme immunoassay system. The free androgen index (FAI) was calculated using the following formula: testosterone $(\mathrm{nmol} / \mathrm{l}) / \mathrm{SHBG} \mathrm{nmol} / \mathrm{l}) \times 100$. $\mathrm{FT}_{4}$, TSH, and PRL were measured by automated random-access immunoassay analyser (Advia Centaur, Siemens, Erlangen, Germany).

\section{Statistical analyses}

All statistical analyses were performed by the Statistical Package for Social Sciences (SPSS) for Windows version 15 . The continuous data were presented as mean \pm s.D.

Table 1 Clinical characteristics of patients with hirsutism.

\begin{tabular}{lcccc}
\hline & $\begin{array}{c}\text { IH } \\
n=14\end{array}$ & $\begin{array}{c}\text { IHA } \\
n=6\end{array}$ & $\begin{array}{c}\text { PCOS } \\
n=83\end{array}$ & $\begin{array}{c}\text { NCAH } \\
n=2\end{array}$ \\
\hline $\begin{array}{c}\text { Presence of oligomeno- } \\
\text { rrhea or anovulation (\%) }\end{array}$ & 0 & 0 & 63 & 0 \\
$\begin{array}{c}\text { Polycystic ovarian } \\
\text { appearance on USG (\%) }\end{array}$ & 0 & 0 & 91 & 100 \\
$\begin{array}{c}\text { Presence of acne (\%) } \\
\text { Presence of alopecia (\%) }\end{array}$ & 43 & 67 & 46 & 0 \\
\hline
\end{tabular}


Table 2 Demographic characteristics and basal hormone levels of patients with hirsutism.

\begin{tabular}{lcccc}
\hline & IH & IHA & PCOS & NCAH \\
& $n=14$ & $n=6$ & $n=83$ & $n=2$ \\
\hline Age (years) & $27.6 \pm 8.5$ & $22.8 \pm 7.4$ & $23 \pm 6$ & $19 \pm 3$ \\
$\mathrm{BMI}\left(\mathrm{kg} / \mathrm{m}^{2}\right)$ & $26.3 \pm 5.9$ & $26.9 \pm 5.3$ & $26.0 \pm 5.3$ & $22.7 \pm 0.7$ \\
$\mathrm{FGS}$ & $13.4 \pm 4.4$ & $10.8 \pm 4.6$ & $14 \pm 4$ & $16 \pm 2$ \\
$\mathrm{FSH}(3-10.9 \mathrm{mIU} / \mathrm{ml})$ & $6.9 \pm 2.7$ & $6.7 \pm 2.2$ & $5.7 \pm 1.9$ & $5.8 \pm 1.2$ \\
LH $(2.1-12.8 \mathrm{mlU} / \mathrm{ml})$ & $5.9 \pm 3.5$ & $8.4 \pm 9$ & $8.1 \pm 5.8$ & $6.9 \pm 3.1$ \\
Estradiol $(19-246 \mathrm{pg} / \mathrm{ml})$ & $86.2 \pm 54$ & $64.1 \pm 48$ & $79 \pm 70$ & $78 \pm 52$ \\
PRL $(3.4-29.8 \mathrm{ng} / \mathrm{ml})$ & $13.1 \pm 6.5$ & $13.4 \pm 5.8$ & $14.4 \pm 10.4$ & $10.6 \pm 2.2$ \\
Testosterone $(11-80 \mathrm{ng} / \mathrm{dl})$ & $52.5 \pm 15$ & $109 \pm 16$ & $98 \pm 44$ & $166 \pm 4$ \\
FAl & $6.8 \pm 4.5$ & $20.6 \pm 9.4$ & $13.6 \pm 9.4$ & $17.7 \pm 3.5$ \\
Androstenedione & $1.6 \pm 0.5$ & $3.5 \pm 2.2$ & $2.7 \pm 1.3$ & $4.7 \pm 2.5$ \\
$(0.1-3.08 \mathrm{ng} / \mathrm{ml})$ & & & & \\
DHEAS $(1330-4410 \mathrm{ng} / \mathrm{ml})$ & $2283 \pm 998$ & $3688 \pm 853$ & $2950 \pm 1115$ & $4751 \pm 1646$ \\
SHBG $(32-100 \mathrm{nmol} / \mathrm{l})$ & $35 \pm 18$ & $20.5 \pm 6.6$ & $32 \pm 18$ & $33 \pm 5$ \\
\hline
\end{tabular}

\section{Results}

The etiology of hirsutism in the patients was IH in $13 \%$, IHA in $6 \%$, NCAH in $2 \%$, and PCOS in $79 \%$ of the patients. Acromegaly was excluded in the patients as all of them had normal IGF1 levels according to age and sex (data not shown).

Five of 105 patients were suspected to have $\mathrm{NCAH}$ according to ACTH stimulation test results. Basal 17-OHP levels were above $2 \mathrm{ng} / \mathrm{ml}$ in all patients suspicious for NCAH. Peak 17-OHP responses following ACTH administration were found to be $14.4,13.5$, 13.3 , and $43.3 \mathrm{ng} / \mathrm{ml}$ and the latter two were found to have CYP21 (CYP21A2) mutations (patient 1: P453S heterozygote on exon 10 and patient 2: Q318X heterozygote on exon 8). Patients with confirmed diagnosis of NCAH after genetic analysis had the highest baseline 17-OHP levels $(7.8$ and $43.3 \mathrm{ng} / \mathrm{ml}$ for patients 1 and 2 respectively). One of the patients was suspected to have NCAH due to 11- $\beta$ hydroxylase deficiency as baseline and peak 11-S response to ACTH stimulation was 5.4 and $14.7 \mathrm{ng} / \mathrm{ml}$ respectively, but it could not be confirmed with genetic analysis. These three patients without CYP21 and CYP11 mutations were diagnosed as PCOS.

All the patients had suppressed cortisol levels following low-dose dexamethasone administration excluding CS. None of the patients had acromegaly, prolactinoma, adrenal, or ovarian androgen-secreting tumors.

Clinical features and basal hormone levels of patients are summarized in Tables 1 and 2. Cortisol levels following LDDST in the patients are presented in Fig. 1. Cortisol levels after LDDST were $0.35 \pm 0.27$, $0.46 \pm 0.38, \quad 0.48 \pm 0.42$, and $0.15 \pm 0.01 \mu \mathrm{g} / \mathrm{dl}$ respectively in IH, IHA, PCOS, and NCAH groups.

\section{Discussion}

In the routine evaluation of hirsutism, endocrinological disorders such as CS, acromegaly, hyperprolactinemia, and thyroid dysfunction need to be excluded. PRL is recommended to be measured particularly in patients with oligo/amenorrhea. Assessment of CS, acromegaly, and thyroid dysfunction is suggested if other features of these conditions are present (12).

There are striking similarities between CS and one of the most common causes of hirsutism, namely PCOS. Both may be associated with hirsutism, menstrual irregularities, polycystic ovaries, obesity, and insulin resistance (20). Proximal muscle weakness and delicate skin are some clues in favor of CS. However, CS is associated with increased cardiovascular mortality (21). The standardized mortality ratio (SMR) was found to be 1.85-1.9 in patients with CS. SMR was shown to be increased to 3.73 in patients with persistent Cushing's disease after transsphenoidal surgery (22).

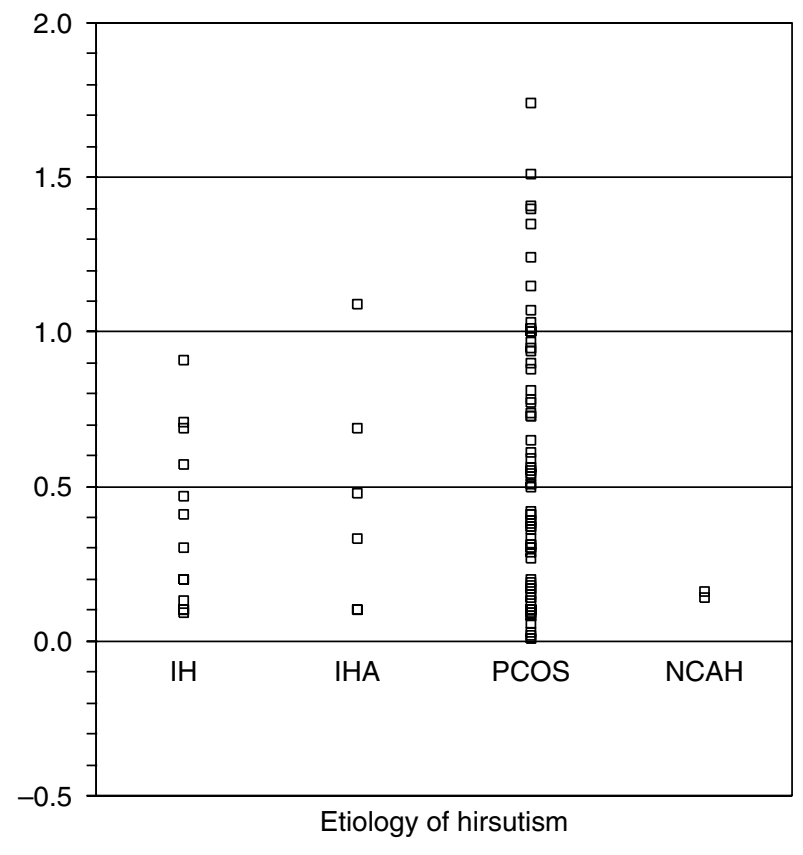

Figure 1 Cortisol levels ( $\mu \mathrm{g} / \mathrm{dl})$ after LDDST in different patient groups. 
Furthermore, persistently increased mortality had been reported even after long-term biochemical remission $(23,24)$. In a recent study, cardiovascular risk was found to be persistent despite dramatic improvements in body composition abnormalities (25). The lack of complete reversibility of associated morbidities and mortality may reinforce the need for revision of CS remission criteria, but at least as important is to limit the duration of exposure to hypercortisolism. Therefore, early diagnosis of CS is of great importance before the presentation of overt cardiovascular or metabolic disorders.

In this study, we screened 105 patients, who were admitted to the Endocrinology Department with the main complaint of hirsutism, for CS irrespective of their suggestive findings of hypercortisolemia. None of the patients was diagnosed as CS by LDDST. In a study by Glintborg et al., whose aim was to compare the metabolic features of patients with hirsutism, only one CS was defined in patients with hirsutism who had clinical findings suggestive of CS. However, the suspicious findings were not mentioned in that study. They used either 24-h urinary free cortisol or overnight dexamethasone suppression test for exclusion and confirmed diagnosis of CS with LDDST (26). Therefore, although there may be overlapping clinical features, CS seems to be rare among patients with hirsutism. As we did not detect any CS in hirsute patients, it is not possible to comment on the suggestive clinical findings.

The prevalence of CS among diabetic patients was reported to range from 0 to $9.4 \%$ depending on the associated features $(7,8,9,27,28,29)$. Clinical features such as being overweight, having poor metabolic control, and hospitalization for DM were found to be associated with increased prevalence of CS in diabetics $(8,27,28)$. Not only patient selection criteria but also differences in test methodology, cut-off values, and cortisol assay used are thought to be responsible for the large range of variation in performed studies (30).

Overnight dexamethasone suppression test has been reported to have a false positivity rate of $20-30 \%$ in previous studies when performed for screening of CS in diabetic individuals $(7,9,10,28)$. The specificity of overnight DST, midnight salivary cortisol, and urinary free cortisol were found to be 90, 96, and $84-92 \%$ respectively for the diagnosis of CS (6). No false positivities were detected in this study presumably due to two reasons: first, skipping over the overnight DST and directly performing LDDST and secondly, different disorders screened.

Screening studies for obese populations usually revealed a low prevalence of CS except for one study that found a prevalence of $9 \%(6,31,32,33)$. Moreover, false-positivity rate was found to be $25 \%$, which resulted in unnecessary further investigations (6). In contrast, CS was found to be present in $4.8 \%$ of patients with osteoporosis and the prevalence increased up to $10.8 \%$ when an accompanying vertebral fracture was found (34). Despite the relatively high prevalence of CS in screening studies, screening of occult CS was suggested to have more cons, like relatively low performance of diagnostic tests, unknown outcomes, and beneficial impact of treatment and acceptability by patients or health care systems (35). The authors also addressed the unknown prevalence of occult CS in hirsute patients in their review (35). Regardless of the study population, screening for CS will diagnose unrecognized cases in cost of increased unnecessary diagnostic test procedures. So cost-effectiveness analysis will be valuable besides performing studies with larger numbers of subjects and using more specific standardized tests. Nevertheless, LDDST seems to be rather specific at least for hirsute patients, as we did not detect any false positivity.

The etiologies of hirsutism in this study were PCOS (79\%), IH (13\%), IHA (6\%), and NCAH ( $2 \%)$, which was similar to the previous literature $(26,35,36,37,38)$. Patients were checked for the presence of ovulation, and hirsute patients with anovulatory regular cycles were included in the PCOS group. We did not detect any androgen-secreting tumor, which can be explained by its rarity as a cause of hirsutism.

In conclusion, routine screening for CS in patients with a referral diagnosis of hirsutism is not required. For the time being, diagnostic tests for CS in hirsute patients cannot be recommended if the patient does not have accompanying clinical stigmata of hypercortisolism.

\section{Declaration of interest}

The authors declare that there is no conflict of interest that could be perceived as prejudicing the impartiality of the research reported.

\section{Funding}

This study is supported by Erciyes University Council of Scientific Investigations (project code: TSU-11-3609).

\section{Acknowledgements}

The authors express their profound gratitude to Prof. Paul Martin Holterhus and Dr Felix Riepe for mutational analysis of $\mathrm{NCAH}$ patients.

\section{References}

1 Escobar-Morreale HF, Carmina E, Dewailly D, Gambineri A, Kelestimur F, Moghetti P, Pugeat M, Qiao J, Wijeyaratne CN, Witchel SF et al. Epidemiology, diagnosis and management of hirsutism: a consensus statement by the Androgen Excess and Polycystic Ovary Syndrome Society. Human Reproduction Update 201218 146-170. (doi:10.1093/humupd/dmr042)

2 Unluhizarci K, Sahin Y \& Kelestimur F. The evaluation and treatment of hirsute women. Women's Health 20051 429-435. (doi:10.2217/17455057.1.3.429)

3 Colao A, Pivonello R, Spiezia S, Faggiano A, Ferone D, Filippella M, Marzullo P, Cerbone G, Siciliani M \& Lombardi G. Persistence of 
increased cardiovascular risk in patients with Cushing's disease after five years of successful cure. Journal of Clinical Endocrinology and Metabolism $1999 \mathbf{8 4}$ 2664-2672. (doi:10.1210/jc.84.8. 2664)

4 Faggiano A, Pivonello R, Spiezia S, De Martino MC, Filippella M, Di Somma C, Lombardi G \& Colao A. Cardiovascular risk factors and common carotid artery caliber and stiffness in patients with Cushing's disease during active disease and 1 year after disease remission. Journal of Clinical Endocrinology and Metabolism $2003 \mathbf{8 8}$ 2527-2533. (doi:10.1210/jc.2002-021558)

5 Feelders RA, Pulgar SJ, Kempel A \& Pereira AM. Management of endocrine disease: the burden of Cushing's disease: clinical and health-related quality of life aspects. European Journal of Endocrinology 2012167 311-326. (doi:10.1530/EJE-11-1095)

6 Baid SK, Rubino D, Sinaii N, Ramsey S, Frank A \& Nieman LK. Specificity of screening tests for Cushing's syndrome in an overweight and obese population. Journal of Clinical Endocrinology and Metabolism 200994 3857-3864. (doi:10.1210/jc.2008-2766)

7 Catargi B, Rigalleau V, Poussin A, Ronci-Chaix N, Bex V, Vergnot V, Gin H, Roger P \& Tabarin A. Occult Cushing's syndrome in type-2 diabetes. Journal of Clinical Endocrinology and Metabolism $2003 \mathbf{8 8}$ 5808-5813. (doi:10.1210/jc.2003-030254)

8 Mullan K, Black N, Thiraviaraj A, Bell PM, Burgess C, Hunter SJ, McCance DR, Leslie H, Sheridan B \& Atkinson AB. Is there value in routine screening for Cushing's syndrome in patients with diabetes? Journal of Clinical Endocrinology and Metabolism 201095 2262-2265. (doi:10.1210/jc.2009-2453)

9 Newsome S, Chen K, Hoang J, Wilson JD, Potter JM \& Hickman PE. Cushing's syndrome in a clinic population with diabetes. Internal Medicine Journal 200838 178-182. (doi:10.1111/j.1445-5994. 2007.01434.x)

10 Reimondo G, Pia A, Allasino B, Tassone F, Bovio S, Borretta G, Angeli A \& Terzolo M. Screening of Cushing's syndrome in adult patients with newly diagnosed diabetes mellitus. Clinical Endocrinology 200767 225-229. (doi:10.1111/j.1365-2265.2007. 02865.x)

11 Unluhizarci K, Kaltsas G \& Kelestimur F. Non polycystic ovary syndrome-related endocrine disorders associated with hirsutism. European Journal of Clinical Investigation $2012 \quad 42 \quad 86-94$. (doi:10.1111/j.1365-2362.2011.02550.x)

12 Martin KA, Chang RJ, Ehrmann DA, Ibanez L, Lobo RA, Rosenfield RL, Shapiro J, Montori VM \& Swiglo BA. Evaluation and treatment of hirsutism in premenopausal women: an endocrine society clinical practice guideline. Journal of Clinical Endocrinology and Metabolism 200893 1105-1120. (doi:10.1210/ jc.2007-2437)

13 Hatch R, Rosenfield RL, Kim MH \& Tredway D. Hirsutism: implications, etiology, and management. American Journal of Obstetrics and Gynecology $1981 \mathbf{1 4 0} 815-830$.

14 Rotterdam ESHRE/ASRM-Sponsored PCOS Consensus Workshop Group. Revised 2003 consensus on diagnostic criteria and longterm health risks related to polycystic ovary syndrome. Fertility and Sterility 200481 19-25.

15 Adams J, Franks S, Polson DW, Mason HD, Abdulwahid N, Tucker M, Morris DV, Price J \& Jacobs HS. Multifollicular ovaries: clinical and endocrine features and response to pulsatile gonadotropin releasing hormone. Lancet 19852 1375-1379. (doi:10.1016/S0140-6736(85)92552-8)

16 Azziz R, Dewailly D \& Owerbach D. Clinical review 56: nonclassic adrenal hyperplasia: current concepts. Journal of Clinical Endocrinology and Metabolism $1994 \mathbf{7 8}$ 810-815. (doi:10.1210/jc.78. 4.810)

17 New MI, Lorenzen F, Lerner AJ, Kohn B, Oberfield SE, Pollack MS, Dupont B, Stoner E, Levy DJ, Pang S et al. Genotyping steroid 21-hydroxylase deficiency: hormonal reference data Journal of Clinical Endocrinology and Metabolism 198357 320-326. (doi:10.1210/jcem-57-2-320)

18 Young J, Tardy V, de la Perriere AB, Bachelot A \& Morel Y. Detection and management of late-onset 21-hydroxylase deficiency in women with hyperandrogenism. Annales d'Endocrinologie 201071 14-18. (doi:10.1016/j.ando.2009.12.009)
19 Kelestimur F, Sahin Y, Ayata D \& Tutus A. The prevalence of nonclassic adrenal hyperplasia due to 11 beta-hydroxylase deficiency among hirsute women in a Turkish population. Clinical Endocrinology 199645 381-384. (doi:10.1046/j.1365-2265.1996. 8150825.x)

20 Kaltsas GA, Korbonits M, Isidori AM, Webb JA, Trainer PJ, Monson JP, Besser GM \& Grossman AB. How common are polycystic ovaries and the polycystic ovarian syndrome in women with Cushing's syndrome? Clinical Endocrinology 2000 53 493-500. (doi:10.1046/j.1365-2265.2000.01117.x)

21 Pivonello R, Faggiano A, Lombardi G \& Colao A. The metabolic syndrome and cardiovascular risk in Cushing's syndrome. Endocrinology and Metabolism Clinics of North America 200534 327-339, viii. (doi:10.1016/j.ecl.2005.01.010)

22 Graversen D, Vestergaard P, Stochholm K, Gravholt CH \& Jorgensen JO. Mortality in Cushing's syndrome: a systematic review and meta-analysis. European Journal of Internal Medicine 201223 278-282. (doi:10.1016/j.ejim.2011.10.013)

23 Bolland MJ, Holdaway IM, Berkeley JE, Lim S, Dransfield WJ, Conaglen JV, Croxson MS, Gamble GD, Hunt PJ \& Toomath RJ. Mortality and morbidity in Cushing's syndrome in New Zealand. Clinical Endocrinology 201175 436-442. (doi:10.1111/j.13652265.2011.04124.x)

24 Hassan-Smith ZK, Sherlock M, Reulen RC, Arlt W, Ayuk J, Toogood AA, Cooper MS, Johnson AP \& Stewart PM. Outcome of Cushing's disease following transsphenoidal surgery in a single center over 20 years. Journal of Clinical Endocrinology and Metabolism 201297 1194-1201. (doi:10.1210/jc.2011-2957)

25 Geer EB, Shen W, Strohmayer E, Post KD \& Freda PU. Body composition and cardiovascular risk markers after remission of Cushing's disease: a prospective study using whole-body MRI. Journal of Clinical Endocrinology and Metabolism 201297 1702-1711. (doi:10.1210/jc.2011-3123)

26 Glintborg D, Henriksen JE, Andersen M, Hagen C, Hangaard J, Rasmussen PE, Schousboe K \& Hermann AP. Prevalence of endocrine diseases and abnormal glucose tolerance tests in 340 Caucasian premenopausal women with hirsutism as the referral diagnosis. Fertility and Sterility 200482 1570-1579. (doi:10.1016/j.fertnstert.2004.06.040)

27 Caetano MS, Vilar L \& Kater CE. Subclinical Cushing's syndrome in populations at risk. Arquivos Brasileiros de Endocrinologia $e$ Metabologia 200751 1185-1190. (doi:10.1590/S0004-2730 2007000800003)

28 Chiodini I, Torlontano M, Scillitani A, Arosio M, Bacci S, Di Lembo S, Epaminonda P, Augello G, Enrini R, Ambrosi B et al. Association of subclinical hypercortisolism with type 2 diabetes mellitus: a case-control study in hospitalized patients. European Journal of Endocrinology 2005153 837-844. (doi:10.1530/eje.1. 02045)

29 Falhammar H. Screening of Cushing's syndrome in patients with type 2 diabetes. New Zealand Medical Journal 2008121 100-102.

30 Krarup T, Krarup T \& Hagen C. Do patients with type 2 diabetes mellitus have an increased prevalence of Cushing's syndrome? Diabetes/Metabolism Research and Reviews 201228 219-227. (doi:10.1002/dmrr.2262)

31 Fierabracci P, Pinchera A, Martinelli S, Scartabelli G, Salvetti G, Giannetti M, Pucci A, Galli G, Ricco I, Querci G et al. Prevalence of endocrine diseases in morbidly obese patients scheduled for bariatric surgery: beyond diabetes. Obesity Surgery 201121 54-60. (doi:10.1007/s11695-010-0297-6)

32 Jankovic D, Wolf P, Anderwald $\mathrm{CH}$, Winhofer Y, PromintzerSchifferl M, Hofer A, Langer F, Prager G, Ludvik B, Gessl A et al. Prevalence of endocrine disorders in morbidly obese patients and the effects of bariatric surgery on endocrine and metabolic parameters. Obesity Surgery 201222 62-69. (doi:10.1007/ s11695-011-0545-4)

33 Tiryakioglu O, Ugurlu S, Yalin S, Yirmibescik S, Caglar E, Yetkin DO \& Kadioglu P. Screening for Cushing's syndrome in obese patients. Clinics 201065 9-13. (doi:10.1590/S180759322010000100003) 
34 Chiodini I, Mascia ML, Muscarella S, Battista C, Minisola S, Arosio M, Santini SA, Guglielmi G, Carnevale V \& Scillitani A. Subclinical hypercortisolism among outpatients referred for osteoporosis. Annals of Internal Medicine 2007147 541-548.

35 Tabarin A \& Perez P. Pros and cons of screening for occult Cushing's syndrome. Nature Reviews. Endocrinology 20117 445-455. (doi:10.1038/nrendo.2011.51)

36 Moran C, Tapia MC, Hernandez E, Vazquez G, Garcia-Hernandez E \& Bermudez JA. Etiological review of hirsutism in 250 patients. Archives of Medical Research 199425 311-314.

37 O'Driscoll JB, Mamtora H, Higginson J, Pollock A, Kane J \& Anderson DC. A prospective study of the prevalence of clearcut endocrine disorders and polycystic ovaries in 350 patients presenting with hirsutism or androgenic alopecia. Clinical Endocrinology 199441 231-236. (doi:10.1111/j.1365-2265. 1994.tb02535.x)

38 Unluhizarci K, Gokce C, Atmaca H, Bayram F \& Kelestimur F. A detailed investigation of hirsutism in a Turkish population: idiopathic hyperandrogenemia as a perplexing issue. Experimental and Clinical Endocrinology \& Diabetes 2004112 504-509. (doi:10.1055/s-2004-821307)

Received 26 October 2012

Revised version received 5 December 2012

Accepted 7 December 2012 